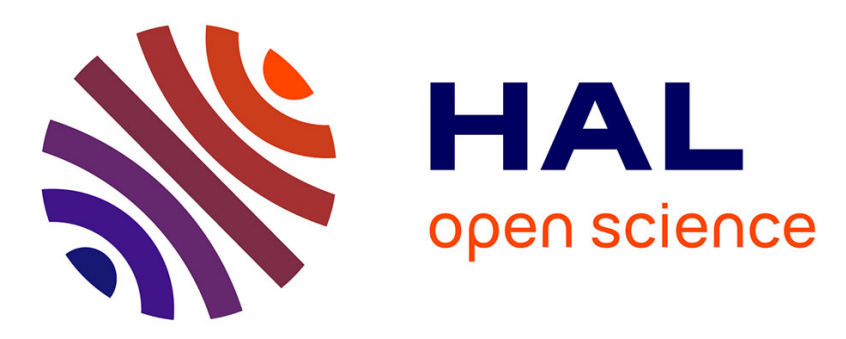

\title{
Spinal effects of oxytocin on uterine motility in anesthetized rats
}

Anissa Benoussaidh, Yves Maurin, Olivier Rampin

\section{To cite this version:}

Anissa Benoussaidh, Yves Maurin, Olivier Rampin. Spinal effects of oxytocin on uterine motility in anesthetized rats. AJP - Regulatory, Integrative and Comparative Physiology, 2004, 287, pp.R446-

R453. hal-02674520

\author{
HAL Id: hal-02674520 \\ https://hal.inrae.fr/hal-02674520
}

Submitted on 31 May 2020

HAL is a multi-disciplinary open access archive for the deposit and dissemination of scientific research documents, whether they are published or not. The documents may come from teaching and research institutions in France or abroad, or from public or private research centers.
L'archive ouverte pluridisciplinaire HAL, est destinée au dépôt et à la diffusion de documents scientifiques de niveau recherche, publiés ou non, émanant des établissements d'enseignement et de recherche français ou étrangers, des laboratoires publics ou privés. 


\title{
Spinal effects of oxytocin on uterine motility in anesthetized rats
}

\author{
Anissa Benoussaidh, Yves Maurin, and Olivier Rampin \\ Analyse et Modélisation en Imagerie Biologique, Institut National de la \\ Recherche Agronomique, Domaine de Vilvert, 78352 Jouy-en-Josas, France
}

Submitted 18 February 2004; accepted in final form 23 March 2004

Benoussaidh, Anissa, Yves Maurin, and Olivier Rampin. Spinal effects of oxytocin on uterine motility in anesthetized rats. Am J Physiol Regul Integr Comp Physiol 287: R446-R453, 2004. First published March 25, 2004; 10.1152/ajpregu.00117.2004.-The rat uterus receives an innervation from the lumbosacral and thoracolumbar segments of the spinal cord. These segments receive descending oxytocinergic projections from the paraventricular nucleus of the hypothalamus. We tested the hypothesis that oxytocin regulates uterine motility through a spinal site of action. Oxytocin was administered in anesthetized female rats either intrathecally at the lumbosacral or thoracolumbar spinal cord levels or intravenously. Uterine activity was revealed by measuring changes of intrauterine pressure using an indwelling balloon placed in one caudal uterine horn. The uterus displayed a spontaneous activity characterized by intrauterine pressure rises, the frequency, amplitude, and duration of which were dependent on the stage of the estrous cycle. Oxytocin delivered at the lumbosacral level affected the frequency (during proestrus, estrus, and diestrus) and amplitude (during proestrus and estrus) of uterine activity. During estrus, oxytocin delivered at the thoracolumbar level affected the frequency, amplitude, and duration of the intrauterine pressure rises. Intravenous oxytocin not only affected intrauterine pressure rises (namely amplitude during proestrus and estrus and frequency and duration during estrus) but also increased the basal tone during estrus. The effects of lumbosacral oxytocin were partly mimicked by the oxytocin agonist $\left[\mathrm{Thr}^{4}, \mathrm{Gly}^{7}\right]$-oxytocin blocked by the oxytocin receptor antagonist atosiban and by hexamethonium. Arginine vasopressin delivered at the lumbosacral level had no effect. These results support our hypothesis that oxytocin released by descending paraventriculo-spinal pathways and acting on spinal oxytocin receptors modulates the activity of the uterus. This regulation is cycle dependent.

urogenital; lumbosacral spinal cord; sexual reflexes

oxyTocin (OT) exerts peripheral contractile effects on the uterus after its release into the systemic circulation by magnocellular neurons of the paraventricular nucleus (29). In addition to this endocrine mode of action, OT may also be released at various levels of the brain stem and spinal cord by paraventriculo-spinal projections originating in parvocellular neurons of the paraventricular nucleus $(5,25,28,30,31,33)$. In the brain stem, this pathway activates motoneurons of the dorsal motor nucleus of the vagus to increase gut motility (6). In the dorsal horn of the spinal cord, OT has been suggested to have antinociceptive effects through the modulation of glutamate release (13). At the lumbosacral level, this pathway has been shown to elicit penile erection in male rats (8) and to participate in the control of bladder activity in female rats (19). Whether OT released at the lumbosacral level affects uterine motility (and to what extent) remained to be shown.

Address for reprint requests and other correspondence: Anissa Benoussaidh, Analyse \& Modélisation en Imagerie Biologique, INRA, Domaine de Vilvert, 78352, Jouy-en-Josas Cedex, France (E-mail: anissa.benoussaidh@jouy.inra.fr).
Uterine activity is dependent on the hormonal status, which varies along the estrous cycle. Receptors for sex steroid hormones (mainly estradiol and progesterone) are present in the uterus (12) and also in the autonomic neural network controlling uterine activity (20). It is thus important to look for a modulatory role of the steroid status on the control of uterine motility by the autonomic nervous system.

To address these two questions, we studied the effects of intrathecally delivered OT on uterine activity in anesthetized rats at the four stages of the estrous cycle. Another paradigm would have used ovariectomized females, in which the hormonal status can be fully controlled. However, both the ovaries and the uterus receive part of their innervation through the ovarian plexus nerve and the superior ovarian nerve, which run in close apposition with the ovary and the upper uterine horn $(1,10)$. Ovariectomy would very likely have lesioned these nerves and thus introduced a bias in our experiments. We consequently used intact female rats.

We also searched for several possible actions of OT, which might interfere with its effects at the lumbosacral level. Thus a possible contaminating effect of intrathecally injected OT diffusing into the systemic circulation was assessed through intravenous administration of OT. The participation of the thoracolumbar sympathetic outflow was evaluated by the intrathecal administration of OT at this level. AVP, a partial agonist on the OT receptor in the central nervous system (24), was also assessed for its possible effects on uterine motility after its application at the lumbosacral level. $\left[\mathrm{Thr}^{4}, \mathrm{Gly}^{7}\right]-\mathrm{OT}$, a selective ligand of OT receptors with agonistic properties (15), and atosiban [1-deamino-2-D-Tyr(OEt)-4-Thr-8-Orn-oxytocin], a synthetic peptide with weak antagonistic properties at OT receptors (7), were also administered intrathecally at the same level. Finally, hexamethonium (HXM), a blocker of nicotinic receptors at autonomic ganglia, was injected intravenously, to interrupt all autonomic information transmission from the spinal cord.

\section{MATERIALS AND METHODS}

Animals. Adult female Sprague-Dawley rats, weighing 250-300 g, were purchased from Charles River (Saint-Aubin-les-Elbeuf, France). Rats were housed in plastic cages containing wood chip bedding. They had free access to commercial pelleted rodent chow (Piètrement, Provins, France) and tap water. Cages were placed in an animal facility maintained at $21^{\circ} \mathrm{C}$ and kept in a $12: 12$-h light-dark cycle (lights on at $8 \mathrm{AM}$ ). Experiments were performed in accordance with the European Economical Community Directive of November 24, 1986 (86/609/EEC) on the use of laboratory animals. All efforts were made to minimize animal suffering and to reduce the number of animals used. Estrous cycle states were identified by histological examination of daily vaginal smears.

The costs of publication of this article were defrayed in part by the payment of page charges. The article must therefore be hereby marked "advertisement" in accordance with 18 U.S.C. Section 1734 solely to indicate this fact. 
Experimental procedure. Rats were anesthetized with an intraperitoneal injection of urethane $(1.2 \mathrm{~g} / \mathrm{kg}$ in sterile water) and their temperature was maintained at $37^{\circ} \mathrm{C}$ using a homeothermic blanket.

To perform intrathecal (it) catheterization, the rat head was fixed in a stereotaxic device and rotated nose downward. The catheter, a polyethylene tubing (PE-10) stretched to $150 \%$ of its original length in hot water, was cut to the required length so that its distal opening reached either the L1-L2 or the L6-S1 segments of the spinal cord. For a female rat weighing $250 \mathrm{~g}$, a $78-\mathrm{mm}$ catheter was used to reach the L6-S1 segments. The skin and neck muscles were incised and retracted. The catheter was inserted into the subarachnoid space through a small hole made in the dura at the level of the atlanto-occipital membrane. It was pushed in the caudal direction and connected to a Hamilton syringe filled with $\mathrm{NaCl} 0.9 \%$.

The jugular vein was catheterized with a polyethylene tubing (PE-10) filled with $\mathrm{NaCl} 0.9 \%$ and connected to a Hamilton syringe also filled with $\mathrm{NaCl} 0.9 \%$. Rats were tracheotomized to facilitate spontaneous breathing.

After a suprapubic midline incision, a small latex balloon, attached to a 1.5-mm-diameter catheter, was inserted through a small incision in the lumen of the left uterine horn and pushed caudally close to the cervix. Because of supplying difficulties in the course of our experiments, two different kinds of balloons were purchased from two different companies. The first kind (Nicomed Amersham Medical Systems, $10.5 \mathrm{~mm}$ long), was used for all experiments of intrathecal lumbosacral and intravenous administrations of OT. The second kind (Balt Extrusion, $9 \mathrm{~mm}$ long) was used for all other experiments (intrathecal thoracolumbar administration, $\left[\mathrm{Thr}^{4}, \mathrm{Gly}^{7}\right]-\mathrm{OT}$, atosiban $\left.+\mathrm{OT}, \mathrm{HXM}+\mathrm{OT}\right)$. It appeared that this second brand was markedly more sensitive than the first one, resulting in a greater frequency and amplitude of intrauterine pressure (IUP) rises measured. This was taken into account and statistical comparisons were made only with results obtained with the same type of balloon.

The balloon and the catheter were filled with sterile water and connected to a pressure transducer (Elcomatic 750, Phymep, France) to monitor the IUP.

Pressure of the balloon was increased and was maintained between 35 and $45 \mathrm{mmHg}$. Pressure signal was amplified (Bionic Instruments, Phymep, France), sent to an analog-to-digital interface, sampled at a frequency of $5 \mathrm{~Hz}$, and stored in a personal computer until offline analysis using Axotape software (Axon Instruments, Union City, CA).

An experiment consisted of the administration to the same rat of 10 $\mu \mathrm{NaCl} 0.9 \%$ followed by successive administrations of $0.3,3,30$, and $300 \mathrm{ng}$ of either OT (it or iv) or AVP (it) or $\left[\mathrm{Thr}^{4}, \mathrm{Gly}^{7}\right]-\mathrm{OT}$ (it) dissolved in $10 \mu \mathrm{l} \mathrm{NaCl} 0.9 \%$. Each administration (including the initial one of $10 \mu \mathrm{l}$ saline) lasted $10-20 \mathrm{~s}$ and was followed by a flush of $25 \mu \mathrm{NaCl} 0.9 \%$. Successive administrations were separated by a period of $15 \mathrm{~min}$. In experiments with atosiban or HXM, a single administration of either compound was done before any other administration (i.e., before the first administration of saline). All the rats of the present study underwent this protocol. Table 1 displays the different groups of rats used in the present study.

At the end of the experiments, rats were killed with an overdose of urethane $(3.6 \mathrm{~g} / \mathrm{kg}$ ip) and perfused with saline through the left cardiac ventricle. The whole spinal cord was then exposed and $10 \mu \mathrm{l}$ of methylene blue were flushed with $10 \mu \mathrm{l}$ of $\mathrm{NaCl} 0.9 \%$ through the intrathecal catheter to mark the exact location of its caudal tip. Analysis of results was only performed in rats in which the catheter faced the L6-S1 or L1-L2 spinal cord segments.

Drug injections. Stock solutions $(10 \mu \mathrm{g} / \mathrm{ml})$ of OT, $\left[\mathrm{Thr}^{4}, \mathrm{Gly}^{7}\right]-$ OT, and AVP (Sigma, Saint-Quentin Fallavier, France) were made using $0.9 \% \mathrm{NaCl}$. Solutions were stored at $-70^{\circ} \mathrm{C}$. The required final concentrations $(0.3,3,30$, and $300 \mathrm{ng}$ in $10 \mu \mathrm{l})$ were freshly prepared on the day of the experiment and kept in ice until used. Atosiban (Ferring, Malmö, Sweden) was dissolved in $\mathrm{NaCl} 0.9 \%$ and injected at the dose of $100 \mathrm{ng}$. HXM (Sigma) was injected at the dose of 20 $\mathrm{mg} / \mathrm{kg}$.

Data analysis. Uterine activity was characterized by episodes of uterine contractions separated by periods of silence. A uterine contraction was characterized by a transient rise of IUP pressure (IUP rise) of an amplitude $>2 \mathrm{mmHg}$, which corresponded to a clearly identifiable peak on the recording trace. Lower IUP increases could not reliably be distinguished from the baseline variations. The frequency of IUP rises (number/min), their amplitude (increase above the basal level expressed in $\mathrm{mmHg}$ ), and their duration (in s) were measured for each animal and averaged (means \pm SE). We also measured the basal tone of IUP, which is the mean \pm SE of all the lowest pressure values recorded between all the consecutive rises during a 15-min period. $n$ contractions recorded during a 15-min period corresponds to $n-1$ basal values. The parameters of spontaneous uterine activity were compared with those measured after $\mathrm{NaCl}$ injection using a Student's paired $t$-test or a Wilcoxon test depending on whether the data were normally distributed or not. Multiple comparisons between groups, compounds, and doses were made using one-way repeated-measures ANOVA in case of a normal distribution of the data or using a $\chi^{2}$ test otherwise. Post hoc analysis was made using the Holm-Sidak method in the former situation or, in the latter one, either a Student-Newman-Keuls test for all pairwise comparisons or a Dunn's test for comparisons with the control value. Statistical significance was reached for $P<0.05$.

\section{RESULTS}

Spontaneous contractile activity of the uterus. In the absence of any injection, spontaneous uterine contractions, as revealed by IUP rises, occurred in 22/24 rats. One rat in proestrus and one in estrus did not present any spontaneous contractions. In the rats that displayed uterine contractions $(n=22)$, IUP rises (whatever the stage) occurred at a frequency of $0.85 \pm 0.08 /$ min, with an amplitude of $7.3 \pm 1.0 \mathrm{mmHg}$ and a duration of $41.8 \pm 2.9$ s. Examples of recordings of spontaneous IUP rises at the different stages of the estrous cycle are shown in Fig. 1.

Their parameters varied along the estrous cycle (Table 2). One-way ANOVA showed an effect of the estrus stage on IUP rise frequency $[F(3,18)=8.669, P<0.001]$, amplitude $[F(3,18)=3.590, P=0.034]$, and duration $[F(3,18)=3.511$,

Table 1. Treatments applied to the various experimental groups

\begin{tabular}{lrlll}
\hline \hline \multicolumn{1}{c}{ Drug } & Rats & Route & Injection Site & Dose, ng \\
\hline OT & 24 & it & L6-S1 & $0.3,3,30,300$ \\
OT & 6 & it & L1-L2 & $0.3,3,30,300$ \\
OT & 16 & iv & jugular vein & $0.3,3,30,300$ \\
[Thr ${ }^{4}$ Gly $]$-OT & 6 & it & L6-S1 & $0.3,3,30,300$ \\
AVP & 6 & it & jugular vein + L6-S1 & $0.3,3,30,300$ \\
HXM + OT & 6 & iv + it & L6-S1 & $20 \mathrm{mg} / \mathrm{kg}+0.3,3,30,300$ \\
Atosiban + OT & 6 & it & $100 \mathrm{ng}+0.3,3,30,300$ \\
\hline
\end{tabular}

Intrathecal injections of oxytocin (OT) at the L6-S1 level were carried out on 6 rats/stage of the estrous cycle (24 rats total). For intravenous (iv) OT injections, 4 rats were used per stage. All other experimental conditions were studied only at the estrus stage (6 rats/experimental group). it, Intrathecal. 

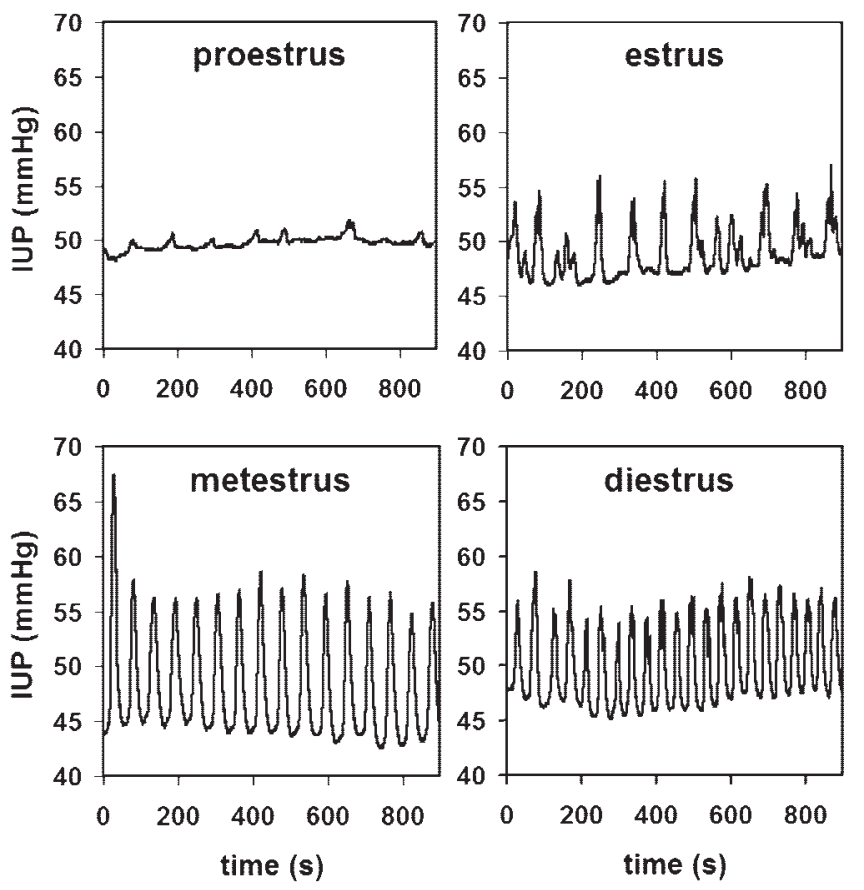

Fig. 1. Examples of spontaneous intrauterine pressure (IUP) rises at the various estrous stages in 4 different anesthetized female rats and recorded using an indwelling balloon placed in the caudal uterine horn. Abscissa: time expressed in seconds; ordinate: pressure expressed in $\mathrm{mmHg}$.

$P=0.037]$. During diestrus, these three parameters were greater than during estrus (Table 2). During metestrus, frequency and amplitude were higher than those recorded during proestrus. In addition, IUP rise frequency in diestrus was higher than in proestrus, and IUP rise amplitude and duration were higher in metestrus compared with estrus (for all these paired comparisons, see significance levels in Table 2). Thus on the basis of these three parameters of IUP rises, the four estrous stages can be divided in two groups: proestrus/estrus and metestrus/diestrus, the former showing IUP rises of lower frequency, amplitude, and duration than the latter.

Intrathecal injections of OT. The results are presented in Fig. 2. During proestrus, $\mathrm{NaCl}$ administered alone exerted a significant inhibitory effect on IUP rise frequency $(0.4 \pm 0.1$ spontaneous rises/min compared with $0.2 \pm 0.1 \mathrm{rises} / \mathrm{min}$ on $\mathrm{NaCl}$ injection, $P=0.028$, Fig. 2 and Table 2). Oxytocin (Fig. 2 , top left) exerted a significant increase of IUP rise frequency $\left[\chi^{2}=16.295, P=0.003\right.$, degrees of freedom $\left.(\mathrm{df})=4\right]$. This effect was attributable only to the dose of $300 \mathrm{ng}$, which induced a significantly higher IUP rise frequency than that measured in the presence of either the vehicle alone (StudentNewman-Keuls test: $P<0.05$ ) or any other dose of OT (Student-Newman-Keuls test: $P<0.05$ vs. all other doses). In estrus, the injection of $\mathrm{NaCl}$ alone did not affect IUP rise frequency $(P=0.099)$. OT, which did not affect the basal tone of IUP $\left(\chi^{2}=8.504, P=0.075\right.$, df $\left.=4\right)$, affected significantly the frequency of IUP rises $\left(\chi^{2}=13.115, P=0.011\right.$, df $\left.=4\right)$. The IUP rise frequency induced by the dose of $300 \mathrm{ng}$ was higher than that induced by $\mathrm{NaCl}$ alone or any other dose of OT (Fig. 2, top left, Student-Newman-Keuls test: $P<0.05$ ).

With respect to the amplitude of IUP rises in proestrus (Fig. 2 , middle left $)$, the vehicle $(\mathrm{NaCl})$ alone had no effect $(P=$ $0.572)$. OT exerted a significant effect $\left(\chi^{2}=14.333, P=\right.$
0.006, df $=4$ ), attributable to the dose of $300 \mathrm{ng}$, which induced a higher amplitude increase than $\mathrm{NaCl}$ or any other dose of OT $(P<0.05$, Student-Newman-Keuls test). In estrus, $\mathrm{NaCl}$ significantly reduced the amplitude of IUP rises compared with spontaneous activity $(2.9 \pm 1.2 \mathrm{mmHg}$ spontaneously vs. $2.1 \pm 1 \mathrm{mmHg}$ on $\mathrm{NaCl}$ injection, $P=0.041)$. OT affected significantly the amplitude of IUP rises (Fig. 2, middle left, $\chi^{2}=16.194, P=0.003$, df $=4$ ). This effect was attributable to the highest dose $(300 \mathrm{ng})$, which increased the amplitude of IUP rises more than $\mathrm{NaCl}$ alone or any other dose of OT ( $P<0.05$, Student-Newman-Keuls test).

With respect to the duration of IUP rises during proestrus/ estrus, neither the vehicle nor OT at any dose exerted any significant effect (Fig. 2, bottom left).

In metestrus, either $\mathrm{NaCl}$ alone or OT remained without any effect on any parameter of IUP rises (Fig. 2, right).

In diestrus, $\mathrm{NaCl}$ alone significantly affected frequency and duration, but not amplitude, of IUP rises (Fig. 2, right, and Table 2, frequency: $1.2 \pm 0.1$ spontaneous rises/min compared with $1.1 \pm 0.1$ on $\mathrm{NaCl}$ injection, $P=0.031$; duration: $47.0 \pm$ $4 \mathrm{~s}$ for the spontaneous rises compared with $52.6 \pm 5.9 \mathrm{~s}$ on $\mathrm{NaCl}$ injection, $P=0.045)$. OT exerted a significant effect on IUP rise frequency (Fig. 2, top right, $\chi^{2}=10.631, P=0.031$, df $=4)$, because of a slight inhibition elicited by the doses of 3 and $30 \mathrm{ng}(P<0.05$, Dunn's test $)$. OT remained without effect on either the amplitude or the duration of IUP rises in diestrus (Fig. 2, middle and bottom right).

Intravenous injections of OT. OT was also administered intravenously at the four estrous stages. The results are presented in Table 3. The vehicle alone was devoid of effect on spontaneous uterine motility, whatever the stage (data not shown).

In proestrus, OT (iv) affected significantly the amplitude of IUP rises $[F(4,12)=4.437, P=0.02]$. This effect was due to the three highest doses $(3,30$, and $300 \mathrm{ng})$, which increased the amplitude compared with $\mathrm{NaCl}$ alone $(P=0.014, P=0.03$, and $P=0.011$, respectively, Holm-Sidak test). In addition, the effect of $30 \mathrm{ng}$ OT was higher than that of $3 \mathrm{ng}(P=0.039$, Holm-Sidak test). OT (iv) exerted no effect on either frequency or duration of IUP rises.

Table 2. Characteristics of spontaneous IUP rises at various stages of the estrous cycle

\begin{tabular}{lclcc}
\hline \hline \multicolumn{1}{c}{ Stage } & Rats & Frequency & Amplitude & Duration \\
\hline Proestrus & 5 & $0.5 \pm 0.1$ & $5.2 \pm 1.8$ & $36 \pm 6$ \\
& 6 & $0.4 \pm 0.1$ & $4.3 \pm 1.7$ & $30 \pm 7$ \\
Estrus & 5 & $0.7 \pm 0.03$ & $3.5 \pm 1.2$ & $31 \pm 7$ \\
& 6 & $0.6 \pm 0.1$ & $2.9 \pm 1.2$ & $26 \pm 8$ \\
Metestrus & 6 & $0.9 \pm 0.1^{\mathrm{a}}$ & $10.6 \pm 2.3^{\mathrm{de}}$ & $51 \pm 3^{\mathrm{f}}$ \\
Diestrus & 6 & $1.2 \pm 0.1^{\mathrm{bc}}$ & $8.8 \pm 1.1^{\mathrm{e}}$ & $47 \pm 4^{\mathrm{f}}$ \\
\hline
\end{tabular}

Values are means \pm SE. Frequency of uterine contractions is expressed in intrauterine pressure (IUP) rises/min, their amplitude in $\mathrm{mmHg}$, and their duration in s. In each of the proestrus and estrus stage groups, 1 rat did not present spontaneous uterine contractions. Consequently the number of rats exhibiting a spontaneous activity is 5 (first line of results for proestrus and estrus groups). However, because these 2 spontaneously inactive rats responded to the administration of OT, they were included in all subsequent statistical analysis. Second line of results $(n=6)$ is the means \pm SE of the frequency, amplitude, and duration when the 0 value for these 2 rats was included. ${ }^{\mathrm{a}} P<0.01$ vs. proestrus; ${ }^{\mathrm{b}} P<0.001$ vs. proestrus; ${ }^{\mathrm{c}} P<0.01$ vs. estrus; ${ }^{\mathrm{d}} P<0.05$ vs. proestrus; ${ }^{\mathrm{e}} P<0.05$ vs. estrus; ${ }^{\mathrm{f}} P<0.05$ vs. estrus. All statistical comparisons vs. the $n=5$ value. 

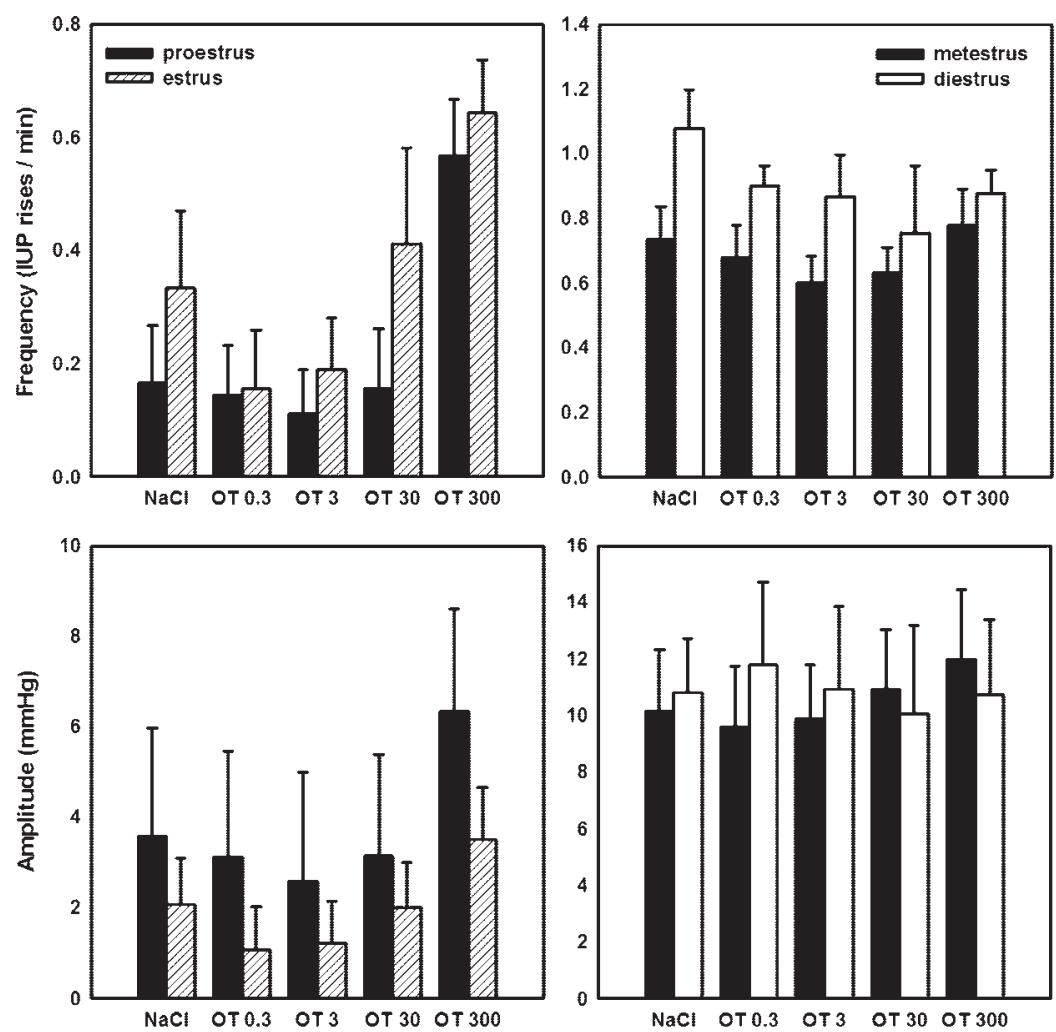

Fig. 2. Histograms displaying the frequency (top), amplitude (middle), and duration (bottom) of the IUP rises on intrathecal injection of oxytocin (OT; 0.3-300 ng) at the lumbosacral level during proestrus/estrus (left) and during metestrus/diestrus $(r i g h t)$. See text for statistical significance.
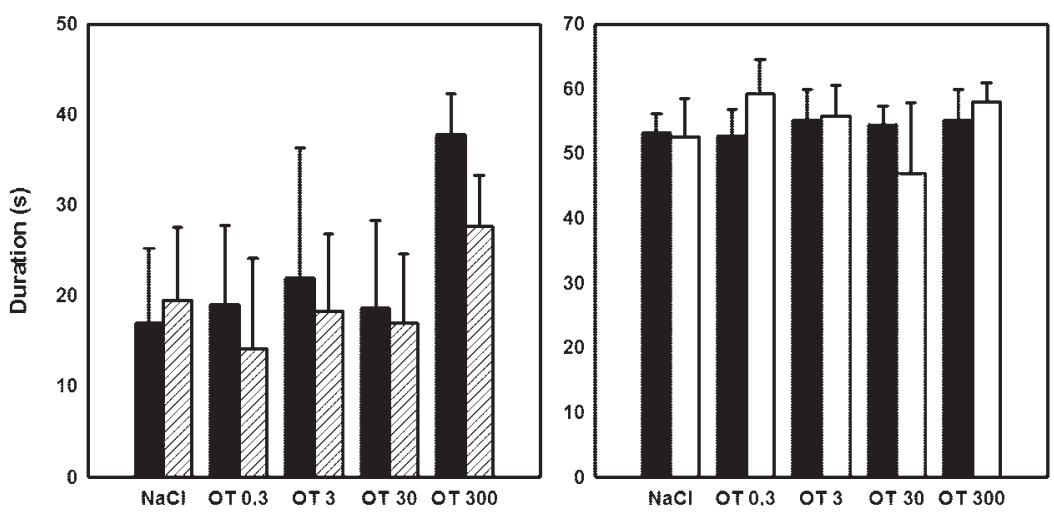

In estrus, OT significantly increased the basal tone of IUP $\left(\chi^{2}=15.241, P=0.004, \mathrm{df}=4\right)$. The doses of 30 and 300 $\mathrm{ng}$ had a greater effect than those of 0.3 and $3 \mathrm{ng}(P<0.05$, Student-Newman-Keuls test). OT also exerted a significant effect on the frequency of the IUP rises $[F(4,12)=14.950$, $P<0.01$, Holm-Sidak test]. This effect was due to 30 and $300 \mathrm{ng}$ OT, which significantly increased the frequency relatively to $\mathrm{NaCl}(P<0.001$ for both doses, Holm-Sidak test), the dose of $0.3 \mathrm{ng}(P<0.01$ for both 30 and $300 \mathrm{ng}$, Holm-Sidak test $)$, and $3 \mathrm{ng}(P=0.004$ and $P=0.001$ when compared with $30 \mathrm{ng}$ and $300 \mathrm{ng}$ respectively, Holm-Sidak test). With regards to the amplitude of IUP rises during estrus, OT also exerted a significant effect $[F(4,12)=$ $15.781, P<0.001]$. Thirty and $300 \mathrm{ng}$ of OT significantly increased this amplitude compared with $\mathrm{NaCl}(P<0.001$ for both doses, Holm-Sidak test $), 0.3 \mathrm{ng}(P<0.001$ for both doses, Holm-Sidak test), and $3 \mathrm{ng}(P=0.019$ when compared with $300 \mathrm{ng}$ and $P=0.029$ when compared with 30 ng, Holm-Sidak test). Finally, 3 ng OT also elicited an increase of IUP rise amplitude that was greater than that recorded on $\mathrm{NaCl}$ and $0.3 \mathrm{ng}(P=0.011$ for both, HolmSidak test). OT (iv) had a significant effect on the duration of the IUP rises $[F(4,12)=4.888, P=0.014]$. This effect was due to the 30 and $300 \mathrm{ng}$ doses of OT, which significantly increased the duration relative to $\mathrm{NaCl}$ (30 ng: $P=$ 0.007 and $300 \mathrm{ng}: P=0.006$, Holm-Sidak test) and to 0.3 ng $(30 \mathrm{ng}: P=0.06$ and $300 \mathrm{ng} P=0.005$, Holm-Sidak test).

In metestrus and diestrus, neither $\mathrm{NaCl}$ alone nor OT had any effect on any parameter of IUP rise.

Intrathecal injections of $O T$ at the thoracolumbar level. These injections have been carried out only at the estrus stage. OT did not exert any effect on the basal tone of IUP (data not shown). The results of OT (it) on IUP rises are presented in Table 4. OT significantly affected their frequency $[F(4,20)=$ $4.568, P=0.009]$. The three highest doses $(3,30$, and $300 \mathrm{ng})$ diminished it when compared with $\mathrm{NaCl}$ alone $(P<0.05, P<$ 0.01 , and $P<0.001$, respectively, Holm-Sidak test). Only the 
Table 3. Effects of intravenously delivered OT on IUP

\begin{tabular}{lcccc}
\hline \hline \multicolumn{1}{c}{ Stage } & Rats & Frequency & Amplitude & Duration \\
\hline Proestrus & 4 & & & \\
NaCl & & $0.4 \pm 0.2$ & $2.5 \pm 1.5$ & $25 \pm 14$ \\
OT 0.3 ng & & $0.5 \pm 0.3$ & $5.4 \pm 3.0$ & $31 \pm 12$ \\
OT 3 ng & & $0.7 \pm 0.1$ & $8.7 \pm 3.9^{*}$ & $44 \pm 6$ \\
OT 30 ng & & $1.0 \pm 0.2$ & $10.4 \pm 4.6^{*}$ & $41 \pm 7$ \\
OT 300 ng & & $1.2 \pm 0.3$ & $9.0 \pm 3.9^{*}$ & $37 \pm 8$ \\
Estrus & 4 & $0.2 \pm 0.2$ & $0.9 \pm 0.9$ & $8 \pm 8$ \\
NaCl & & $0.1 \pm 0.1$ & $0.9 \pm 0.9$ & $6 \pm 6$ \\
OT 0.3 ng & & $0.4 \pm 0.2$ & $3.3 \pm 1.8$ & $22 \pm 8$ \\
OT 3 ng & & $1.1 \pm 0.2 \dagger$ & $5.3 \pm 1.6 \ddagger$ & $30 \pm 3 \dagger$ \\
OT 30 ng & & $1.2 \pm 0.1 \dagger$ & $5.5 \pm 1.7 \ddagger$ & $30 \pm 4 \dagger$ \\
OT 300 ng & 4 & & & \\
Metestrus & & $1.0 \pm 0.1$ & $14.5 \pm 4.1$ & $43 \pm 5$ \\
NaCl & & $0.9 \pm 0.1$ & $12.9 \pm 3.5$ & $42 \pm 7$ \\
OT 0.3 ng & & $1.0 \pm 0.1$ & $11.3 \pm 2.2$ & $42 \pm 8$ \\
OT 3 ng & & $1.1 \pm 0.1$ & $11.2 \pm 2.2$ & $40 \pm 7$ \\
OT 30 ng & & $1.0 \pm 0.1$ & $20.2 \pm 8.8$ & $43 \pm 3$ \\
OT 300 ng & & & & \\
Diestrus & & $1.0 \pm 0.1$ & $7.4 \pm 0.7$ & $43 \pm 7$ \\
NaCl & & $0.9 \pm 0.1$ & $7.1 \pm 1.6$ & $45 \pm 7$ \\
OT 0.3 ng & & $0.9 \pm 0.1$ & $10.5 \pm 1.4$ & $46 \pm 7$ \\
OT 3 ng & & $1.0 \pm 0.1$ & $10.4 \pm 2.2$ & $47 \pm 6$ \\
OT 30 ng & & $0.8 \pm 0.1$ & $9.5 \pm 3.0$ & $44 \pm 8$ \\
OT 300 ng & & & \\
\hline
\end{tabular}

Values are means \pm SE. Frequency of uterine contractions is expressed in IUP rises/min, their amplitude in $\mathrm{mmHg}$, and their duration in $\mathrm{s} . * P<0.05$; $\dagger P<0.01, \ddagger P<0.001$ vs. corresponding $\mathrm{NaCl}$ value (Holm-Sidak test).

highest dose affected the amplitude $\left(\chi^{2}=18.359, P=0.001\right.$, $\mathrm{df}=4)$ and the duration $[F(4,20)=6.06, P=0.02$, HolmSidak test] of the IUP rises.

Specificity of OT effects at the lumbosacral level. All the following measures, presented in Table 5, were performed only in the estrus stage.

$\left[\mathrm{Thr}^{4}, \mathrm{Gly}^{7}\right]$-OT was devoid of any effect on the frequency and duration of the IUP rises, but significantly affected their amplitude $[F(4,20)=19.244, P<0.001$, Table 5]. This effect was biphasic; the doses of 0.3 and $3 \mathrm{ng}$ agonist diminished the amplitude of the response with the vehicle alone $(P=0.008$ and $P=0.034$, respectively, Holm-Sidak test), whereas the dose of $300 \mathrm{ng}$ increased it $(P<0.001$, Holm-Sidak test $)$.

Atosiban, administered alone, did not affect any parameter of the spontaneous IUP rises. It completely antagonized the OT effect on the frequency of IUP rises (Table 5) but not fully their amplitude. Indeed $300 \mathrm{ng}$ OT, in the presence of atosiban, still induced half of the amplitude increase observed in its absence

Table 4. Effects of OT delivered intrathecally at the thoracolumbar level on IUP rises

\begin{tabular}{lcccc}
\hline \hline \multicolumn{1}{c}{ Stage } & Rats & Frequency & Amplitude & Duration \\
\hline Estrus & 6 & & & \\
$\mathrm{NaCl}$ & & $1.0 \pm 0.1$ & $8.9 \pm 3.2$ & $19 \pm 1$ \\
OT 0.3 ng & & $0.9 \pm 0.1$ & $10.0 \pm 4.6$ & $19 \pm 2$ \\
OT 3 ng & & $0.9 \pm 0.1 *$ & $10.7 \pm 4.5$ & $19 \pm 1$ \\
OT 30 ng & & $0.8 \pm 0.1 \dagger$ & $12.7 \pm 4.7$ & $21 \pm 1$ \\
OT 300 ng & & $0.7 \pm 0.1 \ddagger$ & $19.4 \pm 7.4 \S$ & $26 \pm 2 \ddagger$ \\
\hline
\end{tabular}

Values are means \pm SE. Frequency of uterine contractions is expressed in IUP rises/min, their amplitude in $\mathrm{mmHg}$, and their duration in $\mathrm{s}$. $* P<0.05$; $\dagger P<0.01 ; \ddagger P<0.001$ vs. corresponding $\mathrm{NaCl}$ value (Holm-Sidak test); $\S P<$ 0.05 vs. corresponding $\mathrm{NaCl}$ value (Student-Newman-Keuls test).
Table 5. Effects of $\left[\mathrm{Thr}^{4}, \mathrm{Gly}^{7}\right]-O T$, atosiban + OT, AVP, and $H X M+O T$ on IUP rises

\begin{tabular}{|c|c|c|c|c|}
\hline Treatment & Rats & Frequency & Amplitude & Duration \\
\hline Estrus & 6 & & & \\
\hline $\mathrm{NaCl}$ & & $1.1 \pm 0.1$ & $5.9 \pm 1.4$ & $26 \pm 3$ \\
\hline$\left[\mathrm{Thr}^{4}, \mathrm{Gly}^{7}\right]-\mathrm{OT} 0.3 \mathrm{ng}$ & & $1.0 \pm 0.1$ & $4.7 \pm 1.0^{\mathrm{b}}$ & $24 \pm 2$ \\
\hline$\left[\mathrm{Thr}^{4}\right.$, Gly $\left.^{7}\right]$-OT $3 \mathrm{ng}$ & & $0.9 \pm 0.1$ & $5.0 \pm 1.0^{\mathrm{a}}$ & $25 \pm 3$ \\
\hline$\left[\mathrm{Thr}^{4}, \mathrm{Gly}^{7}\right]$-OT $30 \mathrm{ng}$ & & $0.9 \pm 0.2$ & $5.6 \pm 1.0$ & $23 \pm 2$ \\
\hline$\left[\mathrm{Thr}^{4}\right.$, Gly $\left.^{7}\right]-\mathrm{OT} 300 \mathrm{ng}$ & & $1.0 \pm 0.2$ & $7.9 \pm 1.4^{\mathrm{c}}$ & $25 \pm 1$ \\
\hline Estrus & 6 & & & \\
\hline Spontaneous & & $1.3 \pm 0.1$ & $9.6 \pm 0.6$ & $19 \pm 2$ \\
\hline Atosiban & & $1.0 \pm 0.1$ & $9.4 \pm 1.1$ & $18 \pm 2$ \\
\hline Atosiban $+\mathrm{NaCl}$ & & $1.0 \pm 0.3$ & $8.9 \pm 1.4$ & $18 \pm 1$ \\
\hline Atosiban + OT $0.3 \mathrm{ng}$ & & $0.9 \pm 0.2$ & $9.2 \pm 1.4$ & $16 \pm 2$ \\
\hline Atosiban + OT $3 \mathrm{ng}$ & & $1.0 \pm 02$ & $10.1 \pm 2.0$ & $17 \pm 2$ \\
\hline Atosiban + OT $30 \mathrm{ng}$ & & $1.1 \pm 0.2$ & $10.0 \pm 1.8$ & $18 \pm 2$ \\
\hline Atosiban + OT $300 \mathrm{ng}$ & & $1.1 \pm 0.3$ & $12.7 \pm 2.4^{\mathrm{d}}$ & $18 \pm 2$ \\
\hline Estrus & 6 & & & \\
\hline $\mathrm{NaCl}$ & & $1.0 \pm 0.1$ & $5.7 \pm 1.2$ & $22 \pm 3$ \\
\hline AVP $0.3 \mathrm{ng}$ & & $0.9 \pm 0.1$ & $5.6 \pm 1.0$ & $23 \pm 2$ \\
\hline AVP $3 \mathrm{ng}$ & & $0.8 \pm 0.1$ & $5.3 \pm 0.9$ & $22 \pm 3$ \\
\hline AVP $30 \mathrm{ng}$ & & $0.9 \pm 0.2$ & $5.0 \pm 0.6$ & $18 \pm 1$ \\
\hline AVP $300 \mathrm{ng}$ & & $0.9 \pm 0.2$ & $5.5 \pm 0.8$ & $20 \pm 2$ \\
\hline Estrus & 6 & & & \\
\hline Spontaneous & & $1.3 \pm 0.1$ & $7.0 \pm 1.3$ & $16 \pm 2$ \\
\hline HXM & & $1.3 \pm 0.2$ & $11.7 \pm 2.3^{\mathrm{e}}$ & $22 \pm 2$ \\
\hline $\mathrm{HXM}+\mathrm{NaCl}$ & & $1.3 \pm 0.1$ & $12.3 \pm 3.4$ & $20 \pm 4$ \\
\hline $\mathrm{HXM}+\mathrm{OT} 0.3 \mathrm{ng}$ & & $1.2 \pm 0.1$ & $12.9 \pm 3.8$ & $20 \pm 4$ \\
\hline $\mathrm{HXM}+\mathrm{OT} 3 \mathrm{ng}$ & & $1.3 \pm 0.2$ & $12.4 \pm 3.0$ & $19 \pm 4$ \\
\hline $\mathrm{HXM}+\mathrm{OT} 30 \mathrm{ng}$ & & $1.2 \pm 0.2$ & $13.4 \pm 2.5$ & $21 \pm 5$ \\
\hline $\mathrm{HXM}+\mathrm{OT} 300 \mathrm{ng}$ & & $1.3 \pm 0.2$ & $14.5 \pm 2.1$ & $20 \pm 3$ \\
\hline
\end{tabular}

Values are means \pm SE. Frequency of uterine contractions is expressed in IUP rises/min, their amplitude in $\mathrm{mmHg}$, and their duration in $\mathrm{s}$. HXM, hexamethonium. ${ }^{\mathrm{a}} P<0.05$; ${ }^{\mathrm{b}} P<0.01 ;{ }^{\mathrm{c}} P<0.001$ vs. corresponding control (NaCl alone, Holm-Sidak method); ${ }^{\mathrm{d}} P<0.05$ vs. corresponding control $(\mathrm{NaCl}$ alone, Student-Newman-Keuls test); ${ }^{\mathrm{e}} P<0.05$ vs. spontaneous activity (Student-Newman-Keuls test).

[35\% with atosiban (Table 5) to be compared with $67 \%$ in its absence; Fig. 2, middle left].

AVP, whatever its dose, did not exert any action on IUP rises (Table 5).

HXM alone did not modify either the frequency or the duration of spontaneous IUP rises (Table 5); however, it increased significantly their amplitude $(P=0.007$, Student's paired $t$-test). HXM antagonized the OT effect on the amplitude of IUP rises.

\section{DISCUSSION}

We studied the spinal control of uterine motility in the anesthetized female rat model at all stages of the estrous cycle by using IUP as a reliable index of uterine activity. In this model, we characterized the effects of OT intrathecally applied at the lumbosacral level. Uterine activity has been studied in various rat models, either by electromyography $(11,34)$ or by IUP measures $(9,11,27)$. Electromyography does not provide a measure of the force exerted by the uterus. The studies using IUP measures (which is a reliable index of the actual uterine force) have not been carried out at all stages of the cycle. The originality of our approach lies in the systematic measurement of the uterine contractions at the various stages of the estrous cycle and the statistical characterization of the IUP rise parameters. It appeared that these parameters significantly varied 
along the estrous cycle. Therefore, the effects of OT were separately analyzed during the four stages. OT was administered in solution in saline. This procedure has been successfully used previously by other authors (19) who did not mention any effect of saline alone. Recently, we also diluted OT in saline (8) to study the spinal control of penile erection and we did not observe any effect of intrathecally administered saline on intracavernous pressure. At variance with these observations, in the present study, saline alone exerted a significant inhibition of uterine contractions that affected their frequency during proestrus, their amplitude during estrus, and both frequency and duration in diestrus. No effect was detected in metestrus. Thus $\mathrm{NaCl}$ appeared to exert a complex action that did not affect similarly all estrous stages. We cannot propose any clear hypotheses to explain these results. Nevertheless, in all injections, the quantity (hence the effect) of $\mathrm{NaCl}$ was identical. Consequently, the effects of increasing quantities of OT were very likely due to OT itself and not to its vehicle. In the present experiments, it seemed thus appropriate to compare all results with those measured on saline injections and not with the spontaneous activity. Our results indicated that OT, delivered intrathecally, affected uterine motility mainly during the proestrus and estrus stages and, to a minor extent, during diestrus. In view of the peripheral contractile effects of OT on the uterus, our results might have resulted from its leakage into the blood stream. This possible bias is, however, unlikely. First, the leakage of OT into the circulation has been evaluated by Yashpal and coworkers (38), who estimated it to $0.6 \%$ of the quantity injected intrathecally. In the majority of our experiments, the multiple effects of OT reached statistical significance at a dose of $300 \mathrm{ng}$, which would correspond to a quantity of 2 ng leaking into the blood stream. When administered intravenously at $3 \mathrm{ng}$ (Table 3 ), OT did not induce any effect on uterine motility but did affect amplitude of IUP rises during proestrus. Second, some effects were induced by intrathecal, but not by intravenous, injections. Indeed, $300 \mathrm{ng}$ OT enhanced the frequency of IUP rises when administered to proestrus rats by intrathecal route but not by the intravenous one (even at the dose of $3 \mathrm{ng}$ iv, which corresponds to the $1 \%$ contamination of $300 \mathrm{ng}$ it). A similar difference was observed for the dose of $30 \mathrm{ng}$ OT in diestrus rats, which inhibited IUP rises when injected intrathecally but was devoid of effect when injected intravenously at a dose 100 times lower $(0.3 \mathrm{ng})$. These conclusions would remain valid even if the contamination reached $10 \%$ of the intrathecally injected OT. A third argument to exclude the contribution of peripheral effects in the action of intrathecally injected OT resides in the basal tone of uterine pressure, which did not change after intrathecal injections, but was significantly heightened on intravenous ones, even at the lowest dose of $0.3 \mathrm{ng}$. No such shift was recorded after intrathecal injections of any dose of OT. Finally, the application of the nicotinic receptor blocker HXM, which completely inhibits all autonomic outflows from the spinal cord, also abolished the effects of OT on uterine motility. Altogether, these results strongly support the hypothesis that intrathecally applied OT exerts its effect on activation of spinal neural networks.

Three main neural circuits participate in the control of the female genital tract: the lumbosacral and cervical parasympathetic pathways and the thoracolumbar sympathetic pathway (21). We tried to verify that OT, injected at the lumbosacral level, did not exert its effects through the activation of thoracolumbar circuits. This was done first by injecting $10 \mu \mathrm{l}$ methylene blue at the lumbosacral level, which revealed that after insertion of the catheter into a particular spinal segment, the dye did not diffuse beyond one segment rostrally and one segment caudally (i.e., L5-S2 for an injection at the L6 or S1 levels). Thus when administered at the lumbosacral level, OT did not diffuse up to the thoracolumbar segments. Another control was to directly assess the effects of OT intrathecally injected at the thoracolumbar level. Whereas OT, injected at both sites during the estrous stage, elicited modifications of uterine motility, lumbosacral injections differed notably from thoracolumbar ones. The former increased the frequency of uterine contractions at $300 \mathrm{ng}$, but had no effect on their duration, whereas the latter diminished their frequency at 3,30, and $300 \mathrm{ng}$ and augmented their duration at $300 \mathrm{ng}$. Thus, although both spinal locations control uterine motility via the hypogastric and pelvic nerves (27), respectively, OT appeared to have opposite effects on the frequency and duration of uterine contractions depending on its site of application. Consequently we can exclude the rostral diffusion of OT injected into the lumbosacral cord to the thoracolumbar level. Our results do not allow us to propose any hypothesis concerning the selective recruitment of these two spinal levels by descending OTergic fibers. We can nevertheless note that these two levels differ in the nature of their uterine sensory afferent fibers: exclusively nonnociceptive ones for the lumbosacral level and nociceptive ones for the thoracolumbar level (2). In view of the proposed antinociceptive effect of OT (39), it is possible that lowering the frequency of uterine contractions may be a modality of its thoracolumbar site of action. Altogether, it is very likely that in our experiments, OT, applied intrathecally at the lumbosacral level, exerted its effects by the activation of a neural network located in the lumbosacral segments.

Our final control consisted in checking that OT effects were solely mediated by OT receptors in the lumbosacral spinal cord. Indeed, in the central nervous system, OT is a partial agonist of AVP receptors and AVP acts on OT receptors (24). It is also known that lumbosacral spinal segments contain both OT and AVP receptors $(36,37)$. Consequently, during estrus, we evaluated the effects of the specific OT receptor agonist $\left[\mathrm{Thr}^{4}, \mathrm{Gly}^{7}\right]-\mathrm{OT}$, the partial agonist AVP, and the OT receptor antagonist atosiban on IUP rises. $\left[\mathrm{Thr}^{4}, \mathrm{Gly}^{7}\right]$-OT partially mimicked the effects of OT by affecting the amplitude of IUP rises (but not their frequency, at variance with OT itself). AVP was devoid of effect on any parameter of IUP rises. Finally, atosiban blocked the effects of OT on uterine activity at all doses but the highest one (300 ng). The weak affinity of atosiban for the rat OT receptor might explain its partial antagonistic effect. Taken together, our results indicate that the effects of OT on uterine motility are due to a specific interaction with OT receptors in the lumbosacral spinal cord.

OT was devoid of effect in the metestrus stage, had a moderate effect during diestrus (lowering the frequency of IUP rises), and affected principally the proestrus and estrus stages. During these two stages, both the frequency and the amplitude of uterine contractions were increased by $300 \mathrm{ng}$ OT. It is noteworthy that the duration of the contractions was never modified by OT. Thus the time course of uterine reactivity to intrathecal OT paralleled that to peripheral OT, i.e., no reac- 
tivity during metestrus, limited reactivity during diestrus, and the greatest sensitivity during proestrus and estrus. The response of uterus to circulating OT during the estrous cycle depends on both the intensity of the stimulus (concentration of circulating OT) and the sensitivity of the uterus (OT receptors). These two factors simultaneously vary along the estrous cycle $(18,26)$. In the present report, we show that the uterine response to intrathecal OT also varied along the estrous cycle. Intrathecally injected OT recruits autonomic pathways, which relay in the paracervical ganglion and release a variety of neurotransmitters in the uterus (35). It has been shown that the affinity and/or number of uterine receptors for neurotransmitters of the autonomic nervous system change along the estrous cycle in rats $(3,4,14,16,35)$. This variable sensitivity of the receptive organ may contribute to explain the differential effects of intrathecal OT at the various stages. However, it has been shown that the intensity of the stimulus also changes. Indeed, the amount of OT varies in the lumbosacral spinal cord along the estrous cycle (17). Our observation that the uterine response to the same quantity of OT varies along the cycle strongly suggests that the number and/or affinity of spinal OT receptors also vary. Finally, the neural control of uterine motility appears to comply with regulatory mechanisms similar to those of the endocrine control: a simultaneous variation of the sensitivity of the target and of the intensity of the stimulus.

In conclusion, our results indicate that OT exerts a control of uterine activity through the lumbosacral segments of the spinal cord. This clearly resembles the control exerted by OT on penile erection in male rats (8) and the effects of OT on the spinal control of the bladder in female rats (19), strongly suggesting that the central nervous system uses the same neuronal circuits to control urogenital functions in male and female rats. The uterus receives an autonomic innervation from the thoracolumbar and the lumbosacral segments of the spinal cord (22). The sole source of OT in these spinal cord segments is the paraventricular nucleus of the hypothalamus $(5,23,32$, $33)$. We show here that OT exerts an action on uterine activity via these two segments, although in opposite directions. This raises the question of the mechanisms that selectively trigger these effects, which should probably be searched for in the paraventricular nucleus. Finally, in female rats, the neural control of uterine activity by OT appears to depend on the hormonal status. This neural control is added to the endocrine control exerted by circulating OT. Experiments are under way to address the questions of the significance, importance, and triggering of this neural control.

\section{ACKNOWLEDGMENTS}

The authors gratefully acknowledge M. Costa and B. Barbier for taking care of the animals and N. Jerome for expert technical assistance.

\section{GRANTS}

This work was supported by an institutional grant from Institut National de la Recherche Agronomique and by National Institutes of Health Grant 5R01MH-059811-03 to O. Rampin.

\section{REFERENCES}

1. Baljet B and Drukker J. The extrinsic innervation of the pelvic organs in the female rat. Acta Anat (Basel) 107: 241-267, 1980.

2. Berkley KJ, Robbins A, and Sato Y. Functional differences between afferent fibers in the hypogastric and pelvic nerves innervating female reproductive organs in the rat. $J$ Neurophysiol 69: 533-544, 1993.
3. Boyle FC and Digges KG. Effects of catecholamines on pregnant rat uterus. J Auton Pharmacol 2: 97-102, 1982.

4. Boyle FC and Digges KG. Responses to catecholamines of the rat isolated uterus throughout the natural oestrous cycle. Naunyn Schmiedebergs Arch Pharmacol 321: 56-62, 1982.

5. Buijs RM. Intra- and extrahypothalamic vasopressin and oxytocin pathways in the rat. Pathways to the limbic system, medulla oblongata and spinal cord. Cell Tissue Res 192: 423-435, 1978.

6. Dreifuss JJ, Raggenbass M, Charpak S, Dubois-Dauphin M, and Tribollet E. A role of central oxytocin in autonomic functions: its action in the motor nucleus of the vagus nerve. Brain Res Bull 20: 765-770, 1988 .

7. Fuchs AR, Vangsted A, Ivanisevic M, and Demarest K. Oxytocin antagonist (dTVT) and oxytocin receptors in myometrium and decidua. Am J Perinatol 6: 205-208, 1989.

8. Giuliano F, Bernabe J, McKenna K, Longueville F, and Rampin $\mathbf{O}$. Spinal proerectile effect of oxytocin in anesthetized rats. Am J Physiol Regul Integr Comp Physiol 280: R1870-R1877, 2001.

9. Hotta H, Uchida S, Shimura M, and Suzuki H. Uterine contractility and blood flow are reflexively regulated by cutaneous afferent stimulation in anesthetized rats. J Auton Nerv Syst 75: 23-31, 1999.

10. Houdeau E, Rousseau A, Meusnier C, Prud'homme MJ, and Rousseau JP. Sympathetic innervation of the upper and lower regions of the uterus and cervix in the rat have different origins and routes. J Comp Neurol 399: 403-412, 1998.

11. Ishikawa $\mathbf{M}$ and Fuchs AR. Electrical and mechanical activity of rat uterus in vivo during the estrous cycle. Am J Obstet Gynecol 132: 611-619, 1978.

12. Jensen EV and DeSombre ER. Estrogen-receptor interaction. Science 182: 126-134, 1973.

13. Jo YH, Stoeckel ME, Freund-Mercier MJ, and Schlichter R. Oxytocin modulates glutamatergic synaptic transmission between cultured neonatal spinal cord dorsal horn neurons. J Neurosci 18: 2377-2386, 1998.

14. Kano T. Effects of estrogen and progesterone on adrenoceptors and cyclic nucleotides in rat uterus. Jpn J Pharmacol 32: 535-549, 1982.

15. Lowbridge J, Manning M, Haldar J, and Sawyer WH. Synthesis and some pharmacological properties of [4-threonine, 7-glycine]oxytocin, [1-(L-2-hydroxy-3-mercaptopropanoic acid), 4-threonine, 7-glycine]oxytocin (hydroxy[Thr4, Gly7]oxytocin), and [7-Glycine]oxytocin, peptides with high oxytocic-antidiuretic selectivity. J Med Chem 20: 120-123, 1977.

16. Maltier JP, Benghan-Eyene Y, and Legrand C. Regulation of myometrial beta 2-adrenergic receptors by progesterone and estradiol-17 beta in late pregnant rats. Biol Reprod 40: 531-540, 1989.

17. Miaskowski C, Ong GL, and Haldar J. Cyclic variations in spinal cord levels of oxytocin and vasopressin during the stages of the rat estrous cycle. Endocrinology 120: 1685-1687, 1987.

18. Murata T, Narita K, Honda K, and Higuchi T. Changes of receptor mRNAs for oxytocin and estrogen during the estrous cycle in rat uterus. $J$ Vet Med Sci 65: 707-712, 2003.

19. Pandita RK, Nylen A, and Andersson KE. Oxytocin-induced stimulation and inhibition of bladder activity in normal, conscious rats-influence of nitric oxide synthase inhibition. Neuroscience 85: 1113-1119, 1998.

20. Papka RE and Mowa CN. Estrogen receptors in the spinal cord, sensory ganglia, and pelvic autonomic ganglia. Int Rev Cytol 231: 91-127, 2003.

21. Papka RE and Traurig HH. Autonomic efferent and visceral sensory innervation of the female reproductive system: special reference to neurochemical markers in nerves and ganglionic connections. In: Nervous Control of the Urogenital System, edited by Maggi CA. Chur, Switzerland: Harwood Academic, 1993, p. 423-466.

22. Papka RE, Williams S, Miller KE, Copelin T, and Puri P. CNS location of uterine-related neurons revealed by trans-synaptic tracing with pseudorabies virus and their relation to estrogen receptor-immunoreactive neurons. Neuroscience 84: 935-952, 1998.

23. Puder BA and Papka RE. Hypothalamic paraventricular axons projecting to the female rat lumbosacral spinal cord contain oxytocin immunoreactivity. J Neurosci Res 64: 53-60, 2001.

24. Raggenbass M. Vasopressin- and oxytocin-induced activity in the central nervous system: electrophysiological studies using in-vitro systems. Prog Neurobiol 64: 307-326, 2001.

25. Richard P, Moos F, and Freund-Mercier MJ. Central effects of oxytocin. Physiol Rev 71: 331-370, 1991. 
26. Sarkar DK and Gibbs DM. Cyclic variation of oxytocin in the blood of pituitary portal vessels of rats. Neuroendocrinology 39: 481-483, 1984.

27. Sato S, Hayashi RH, and Garfield RE. Mechanical responses of the rat uterus, cervix, and bladder to stimulation of hypogastric and pelvic nerves in vivo. Biol Reprod 40: 209-219, 1989.

28. Sawchenko PE and Swanson LW. Immunohistochemical identification of neurons in the paraventricular nucleus of the hypothalamus that project to the medulla or to the spinal cord in the rat. J Comp Neurol 205: 260-272, 1982.

29. Silverman AJ and Zimmerman EA. Magnocellular neurosecretory system. Annu Rev Neurosci 6: 357-380, 1983.

30. Sofroniew MV. Projections from vasopressin, oxytocin, and neurophysin neurons to neural targets in the rat and human. J Histochem Cytochem 28: 475-478, 1980.

31. Swanson LW. Immunohistochemical evidence for a neurophysin-containing autonomic pathway arising in the paraventricular nucleus of the hypothalamus. Brain Res 128: 346-353, 1977.

32. Swanson LW and Kuypers HG. The paraventricular nucleus of the hypothalamus: cytoarchitectonic subdivisions and organization of projections to the pituitary, dorsal vagal complex, and spinal cord as demonstrated by retrograde fluorescence double-labeling methods. J Comp Neurol 194: 555-570, 1980 .
33. Swanson LW and McKellar S. The distribution of oxytocin- and neurophysin-stained fibers in the spinal cord of the rat and monkey. J Comp Neurol 188: 87-106, 1979.

34. Toner JP and Adler NT. Influence of mating and vaginocervical stimulation on rat uterine activity. J Reprod Fertil 78: 239-249, 1986.

35. Traurig HH and Papka RE. Autonomic efferent and visceral sensory innervation of the female reproductive system: special reference to the functional roles of nerves in reproductive organs. In: Nervous Control of Urogenital System, edited by Maggi CA. Chur, Switzerland: Harwood Academic, 1993, p. 103-141.

36. Tribollet E, Barberis C, and Arsenijevic Y. Distribution of vasopressin and oxytocin receptors in the rat spinal cord: sex-related differences and effect of castration in pudendal motor nuclei. Neuroscience 78: 499-509, 1997.

37. Veronneau-Longueville F, Rampin O, Freund-Mercier MJ, Tang Y, Calas A, Marson L, McKenna KE, Stoeckel ME, Benoit G, and Giuliano F. Oxytocinergic innervation of autonomic nuclei controlling penile erection in the rat. Neuroscience 93: 1437-1447, 1999.

38. Yashpal K, Gauthier S, and Henry JL. Oxytocin administered intrathecally preferentially increases heart rate rather than arterial pressure in the rat. J Auton Nerv Syst 20: 167-178, 1987.

39. Yu SQ, Lundeberg T, and Yu LC. Involvement of oxytocin in spinal antinociception in rats with inflammation. Brain Res 983: 13-22, 2003.

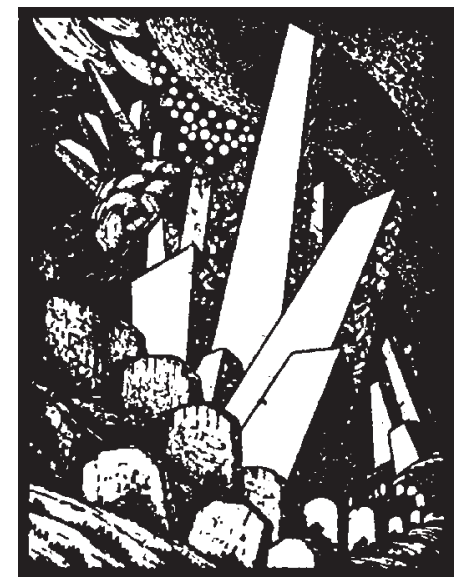

